\title{
Cutaneous metastasis of signet ring cell appendiceal adenocarcinoma: a herald of disease recurrence
}

\author{
Jennifer L. Seyffert ${ }^{1 *}$, Nathan Bibliowicz ${ }^{1}$, Christopher Wong ${ }^{2}$, Michael Wangia ${ }^{1}$
}

\begin{abstract}
${ }^{1}$ Department of Dermatology at Kansas City University of Medicine and Biosciences-Advanced Dermatology and Cosmetic Surgery, Dermatology Residency of Orlando, Orlando, FL

${ }^{2}$ College of Osteopathic Medicine of the Pacific of Western University of Health Sciences, Pomona, CA
\end{abstract}

Received: 08 January 2020

Revised: 04 March 2020

Accepted: 09 March 2020

*Correspondence:

Dr. Jennifer L. Seyffert,

E-mail: Jennifer.seyffert@adcsclinics.com

Copyright: () the author(s), publisher and licensee Medip Academy. This is an open-access article distributed under the terms of the Creative Commons Attribution Non-Commercial License, which permits unrestricted non-commercial use, distribution, and reproduction in any medium, provided the original work is properly cited.

\section{ABSTRACT}

Signet ring cell appendiceal adenocarcinoma (SRCAA) is a rare entity with poor prognosis and high tendency for metastasis to pelvic lymph nodes, ovaries, and peritoneal surfaces. Despite numerous reports of intra-abdominal metastasis, there have been few reported cases of cutaneous SRCAA metastasis. We report a rare case of SRCAA metastatic to the cutaneous abdominal wall in a 67 years old female, which was first presenting sign of disease recurrence.

Keywords: Metastatic signet ring cell appendiceal adenocarcinoma, Cutaneous metastasis, Signet ring cell, Appendiceal adenocarcinoma

\section{INTRODUCTION}

Signet ring cell carcinomas, frequent in the stomach and intestine, are adenocarcinomas with mucus-producing tumor cells. Signet ring cell appendiceal adenocarcinoma (SRCAA) is a rare entity with poor prognosis and high tendency for metastasis to pelvic lymph nodes, ovaries, and peritoneal surfaces. ${ }^{1-6}$ Despite numerous reports of intra-abdominal metastasis, there have been few reported cases of cutaneous SRCAA metastasis. ${ }^{5}$ We report a rare case of SRCAA metastatic to the cutaneous abdominal wall in a 67 years old female, which was first presenting sign of disease recurrence.

\section{CASE REPORT}

A 67 years old female with a history of stage IV signet ring cell appendiceal adenocarcinoma (SRCAA) presented with an erythematous, malodorous, tender eruption extending from her anterior abdominal wall scar that had been locally spreading over the past 3 months. In 2017, the patient had been initially treated with colectomy with ileostomy, and six cycles of leucovorin calcium, fluorouracil, and oxaliplatin (FOLFOX), followed by hyperthermic intraperitoneal chemotherapy (HIPEC). The patient had recurrence and metastatic deposits in her anterior abdominal scar prompting another seven cycles of leucovorin calcium, fluorouracil, and irinotecan (FOLFIRI), followed by radiation to the anterior abdominal wall scar in early 2018. Interval CT and positron emission tomography (PET) scans had remained negative for metastatic disease in the visceral organs, peritoneum, and lymph nodes. Her primary care physician had treated her abdominal rash with a combination of antiviral and antibiotics without improvement.

Upon presentation, physical examination was notable for edematous, erythematous, malodorous nodules coalescing into plaques on the anterior abdomen in the region of her 
anterior abdominal surgical scar (Figure 1). There was no evidence of inguinal lymphadenopathy. A broad cutaneous shave biopsy was performed which demonstrated a dermal proliferation of signet ring cells with abundant mucin and epithelial extension (Figures 2 and 3). Tumor cells were immunoreactive with CDX-2 (Figure 4), AE1/AE3, CK20 (Figure 5), carcinoembryonic antigen (CEA), and epithelial membrane antigen (EMA) stains; tumor cells were negative for CK7, CK5/6, P63, GCDFP-15, and S-100. Colloidal iron stain highlighted intracellular mucin deposition. The histologic features and immunohistochemical profile in this case were compatible with cutaneous metastasis of SRCAA. CEA levels were elevated at $4.7 \mathrm{ng} / \mathrm{ml}$. CT and PET scan remained negative for any intra-abdominal involvement. The patient is currently following with oncology.

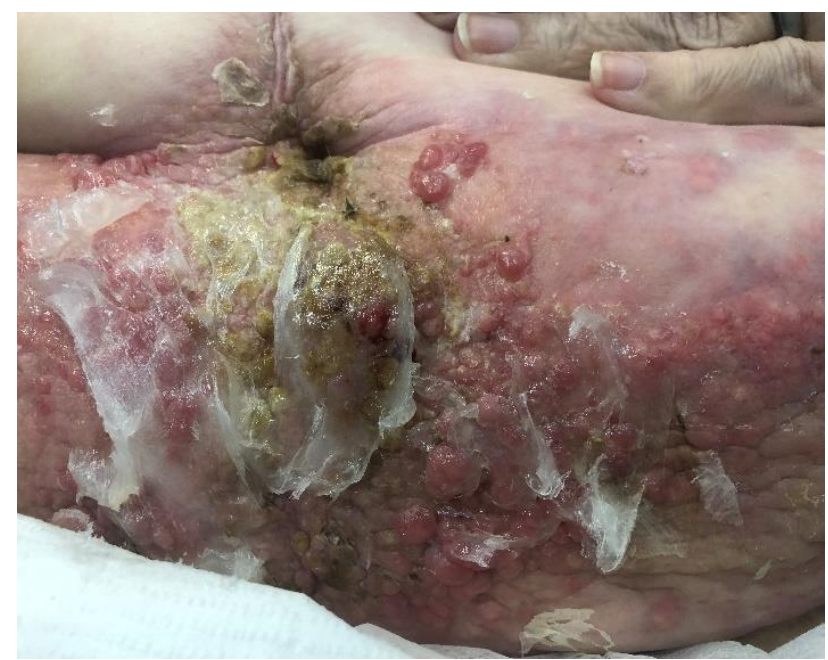

Figure 1: Erythematous nodules coalescing into plaques in the region of the patient's anterior abdominal surgical scar.

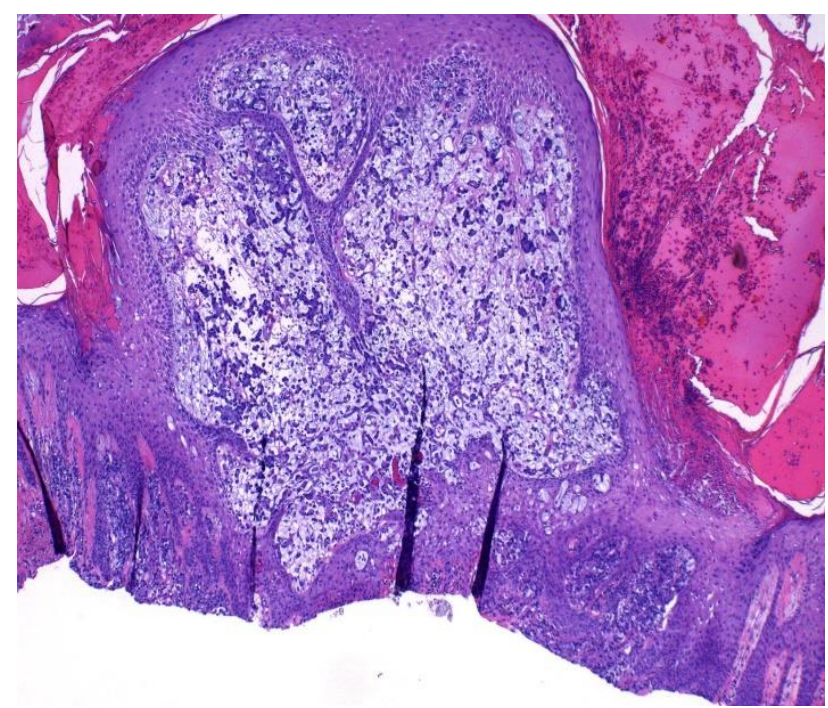

Figure 2: $\mathrm{H}$ and $\mathrm{E}$, low power visualization of dermal proliferation of signet ring cells.

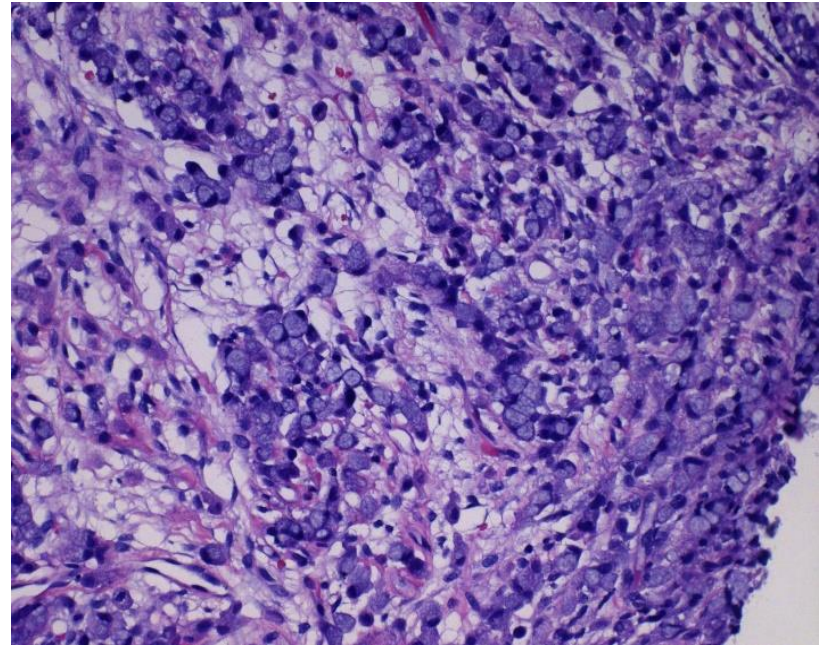

Figure 3: $\mathrm{H}$ and E, high power visualization of signet ring cells with abundant mucin.

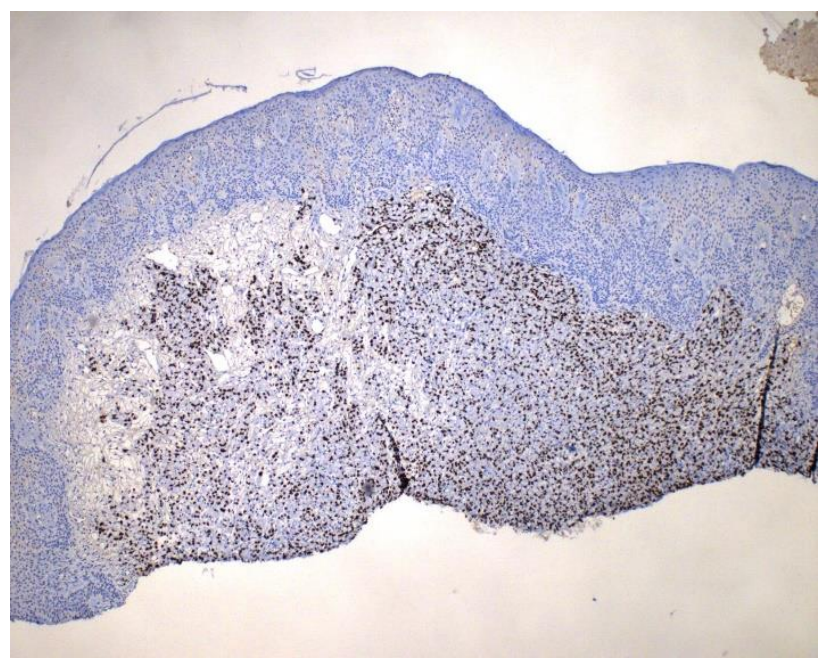

Figure 4: Positive CDX-2 immunohistochemical stain.

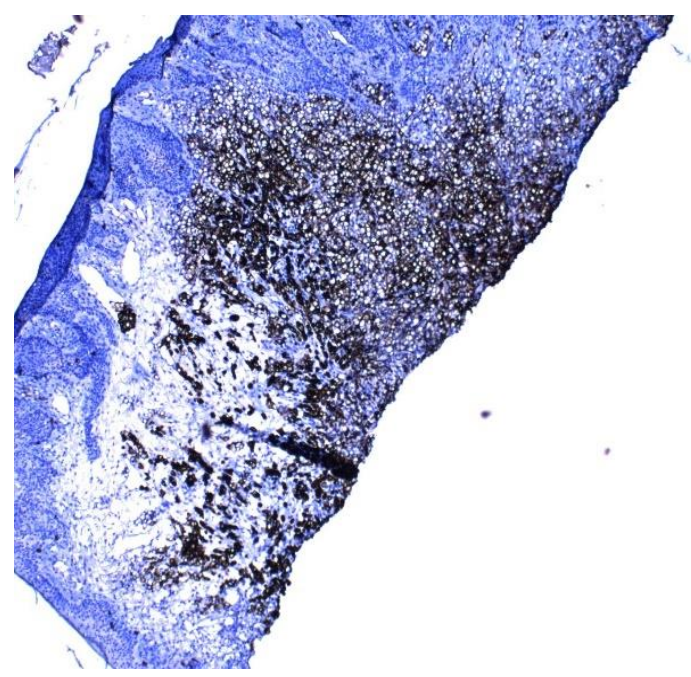

Figure 5: Positive CK20 immunohistochemical stain. 


\section{DISCUSSION}

Signet ring cell carcinomas, frequent in the stomach and intestine, are adenocarcinomas with mucus-producing tumor cells. SRCAA is rare, comprising only $4 \%$ of all primary appendiceal neoplasms. ${ }^{1}$ SRCAA is a clinically aggressive type of cancer that often spreads to the pelvic lymph nodes, ovaries, and peritoneal surfaces by the time of diagnosis. ${ }^{1-6}$ The most common presentation is right lower quadrant abdominal pain mimicking acute appendicitis. ${ }^{7,8}$ Advanced abdomino-pelvic malignancies can also present as a metastatic umbilical nodule, termed a sister Mary Joseph nodule. There have been cases of reported inheritance of signet ring cell carcinomas caused by mutation of $\mathrm{CDH} 1$ gene, which encodes E-cadherin, an important glycoprotein in cell-cell adhesion. ${ }^{9,10}$ Somatic mutations of APC gene have also been reported in gastric signet ring cell carcinoma. ${ }^{11}$

Diagnosis is confirmed with cutaneous biopsy and imaging studies. Histologically, the appearance of signet ring cells result from formation of large vacuoles of mucin that displace the nucleus to the cell's periphery. ${ }^{12}$ Primary cutaneous signet ring cell carcinoma (PCSRCC) is a rare entity of suspected sweat gland origin, which stain positively with MNF116, CA15-3, BCA225, GCDFP15, CEA, CA125, and CK20. ${ }^{13-15,16}$ Given the rarity of PCSRCC, it is important to rule out metastatic primary visceral malignancy.

SRCAA is a histopathologically distinct tumor. ${ }^{4,17}$ Reported cases describe tumor cells demonstrating diffuse, strong immunoreactivity against CK20, CDX-2, MUC-2, CEA, and focal immunopositivity for MUC5AC. . $^{3,18}$ CDX-2 is a useful marker to confirm an appendiceal origin; it can be used in conjunction with CK20, MUC-2, and MUC-5AC for confirmation. ${ }^{19}$ Imaging studies, such as CT scan, are helpful to identify, but not distinguish SRCAA from other histological types of appendiceal carcinomas. On imaging, spread to adjacent organs is evident in $76 \%$ of SRCAA at presentation compared with the mucinous $(63 \%)$ and colonic type $(37 \%)$ carcinomas. ${ }^{20}$

The treatment options for metastatic disease include systemic chemotherapy, hyperthermic intraoperative intraperitoneal chemotherapy, cytoreductive surgery with a peritonectomy, and or a combination of the above treatments. It is controversial whether debulking surgery and intraperitoneal chemotherapy are worthwhile for all aggressive, advanced disease cases. ${ }^{3}$

The prognosis is considered very poor, with a 5 years survival rate of $18 \%$, this is the lowest overall 5 years survival rate of all the subtypes of appendiceal carcinoma. ${ }^{21}$ Those who presented with distant metastatic disease had an even lower 5 years survival rate of $7 \%{ }^{21}$

\section{CONCLUSION}

Cutaneous metastasis of SRCAA is rare and may present as the only herald of disease recurrence. Noting the distinction between primary and metastatic sing ring cell carinomas is of high importance, as the evaluation, management, and prognosis for the two entities are distinct. Given these implications, the dermatologist plays an integral role and should be attentive to these diagnostic possibilities.

\section{Funding: No funding sources Conflict of interest: None declared Ethical approval: Not required}

\section{REFERENCES}

1. Fusari M, Sorrentino N, Bottazzi EC. Primary signet ring cell carcinoma of the appendix mimicking acute appendicitis. Acta Radiol Short Reports. 2012;1(9):1-3.

2. Ruoff C, Hanna L, Zhi W, Shahzad G, Gotlieb V, Saif MW. Cancers of the Appendix: Review of the Literatures. ISRN Oncol. 2011;2011:1-6.

3. Ko YH, Jung CK, Oh SN. Primary signet ring cell carcinoma of the appendix: a rare case report and our 18-year experience. World J Gastroenterol. 2008;14(37):5763-8.

4. Wang HL, Dhall D. Goblet or Signet Ring Cells. Adv Anat Pathol. 2009;16(4):247-54.

5. Bertuzzo VR, Coccolini F, Pinna AD. Peritoneal seeding from appendiceal carcinoma: A case report and review of the literature. World $\mathrm{J}$ Gastrointest Surg. 2010;2(8):265.

6. Ploenes $\mathrm{T}$, Borner $\mathrm{N}$, Kirkpatrick CJ, Heintz A. Neuroendocrine Tumour, Mucinous Adenocarcinoma and Signet-Ring Cell Carcinoma of the Appendix: Three Cases and Review of Literature. Indian J Surg. 2013;75(S1):299-302.

7. Connor SJ, Hanna GB, Frizelle FA. Appendiceal tumors: retrospective clinicopathologic analysis of appendiceal tumors from 7,970 appendectomies. Dis Colon Rectum. 1998;41(1):75-80.

8. Donnell OME, Badger SA, Beattie GC, Carson J, Garstin WIH. Malignant neoplasms of the appendix. Int J Colorectal Dis. 2007;22(10):1239-48.

9. Diffuse gastric cancer/Genetic and Rare Diseases Information Center (GARD) - an NCATS Program. Available at: https://rarediseases.info.nih.gov/ diseases/10334/disease. Accessed November 12, 2018.

10. Muta H, Noguchi M, Kanai Y, Ochiai A, Nawata H, Hirohashi S. E-Cadherin Gene Mutations in Signet Ring Cell Carcinoma of the Stomach. Japanese J Cancer Res. 1996;87(8):843-8.

11. Nakatsuru S, Yanagisawa A, Ichii S. Somatic mutation of the APC gene in gastric cancer: frequent mutations in very well differentiated adenocarcinoma and signet-ring cell carcinoma. Hum Mol Genet. 1992;1(8):559-63. 
12. Pathology Outlines - Signet ring cell carcinoma. http://www.pathologyoutlines.com/topic/colontumor signetring.html. Accessed November 12, 2018.

13. Goldblum JR, Hart WR. Perianal Paget's disease: a histologic and immunohistochemical study of 11 cases with and without associated rectal adenocarcinoma. Am J Surg Pathol. 1998;22(2):170-9.

14. Rosen Y, Kim B, Yermakov VA. Eccrine sweat gland tumor of clear cell origin involving the eyelids. Cancer. 1975;36(3):1034-41.

15. Kuno Y, Numata T, Kanzaki T. Adenocarcinoma with signet ring cells of the axilla showing apocrine features: a case report. Am J Dermatopathol. 1999;21(1):37-41.

16. Kiyohara T, Kumakiri M, Kouraba S, Tokuriki A, Ansai S. Primary cutaneous signet ring cell carcinoma expressing cytokeratin 20 immunoreactivity. J Am Acad Dermatol. 2006;54(3):532-6.

17. Kim HJ, Ha HK, Cho KS. CT features of primary colorectal signet-ring cell carcinoma. J Comput Assist Tomogr. 2001;25(2):225-30.
18. Chu PG, Weiss LM. Immunohistochemical Characterization of Signet-Ring Cell Carcinomas of the Stomach, Breast, and Colon. Am J Clin Pathol. 2004;121(6):884-92.

19. Nonaka D, Kusamura S, Baratti D, Casali P, Younan R, Deraco M. CDX-2 expression in pseudomyxoma peritonei: a clinicopathological study of 42 cases. Histopathology. 2006;49(4):381-7.

20. Zhou M, Yan F, Xu P, Zhang L, Li Q, Ji Y. Mucinous cystadenoma of the appendix: CT findings. Chin Med J (Engl). 2006;119(15):1300-3.

21. Cusker MME, Cote TR, Clegg LX, Sobin LH. Primary malignant neoplasms of the appendix. Cancer. 2002;94(12):3307-12.

Cite this article as: Seyffert JL, Bibliowicz N, Wong C, Wangia M. Cutaneous metastasis of signet ring cell appendiceal adenocarcinoma: a herald of disease recurrence. Int J Res Dermatol 2020;6:406-9. 